\title{
A figura e sua influência nas estratégias de resolução de uma situação problema de Geometria plana
}

\author{
Figure and its influence on problem solving strategies for a flat Geometry \\ problem
}

\author{
Cleusiane Vieira Silva \\ Weslley Igor da Cruz dos Santos
}

\begin{abstract}
Resumo: Neste trabalho, temos por objetivo analisar como uma figura proposta como parte do enunciado de uma situação-problema sobre Geometria plana pode influenciar nos procedimentos de resolução apresentados por alunos ingressantes de um curso de licenciatura em Matemática. Este artigo é um recorte de uma pesquisa, em andamento, que trata do ensino e da aprendizagem da Geometria plana na formação inicial de professores de Matemática. Nele, utilizamos como aporte teórico a Teoria de Registro de Representação Semiótica de Raymond Duval. Desenvolvemos uma pesquisa com abordagem qualitativa, do tipo estudo de caso. Como possíveis resultados, observamos que os estudantes utilizaram-se de modificações mereológicas, posicionais e reconfigurações em seus procedimentos de resolução.
\end{abstract} Observamos ainda que em situações-problema que contenham figuras como parte do enunciado é preciso ter atenção quanto ao objetivo da situação.

Palavras-chave: Situação-problema. Geometria plana. Registro de Representação Semiótica. Congruência.

Abstract: In this paper we aim to analyze how a figure proposed as part of the statement of a problem situation about flat Geometry can influence the resolution procedures presented by students entering a Mathematics degree course. This article is a clipping from an ongoing research that deals with teaching and learning of flat Geometry in the

Cleusiane Vieira Silva Doutora em Educação Matemática (PUC-SP). Professora da Universidade Estadual do Sudoeste da Bahia (UESB), campus Jequié. Bahia, Brasil. $₫$ cleusianesilva@gmail.com

Weslley Igor da Cruz dos Santos Aluno da Licenciatura em Matemática da Universidade Estadual do Sudoeste da Bahia (UESB), campus Jequié. Bahia, Brasil. $\triangle$ weslley santos9@hotmail.com

Recebido em 18/07/2019 Aceito em 15/08/2019

Publicado em 01/09/2019 initial training of math teachers. In it, we use as theoretical contribution Raymond Duval's Semiotic Representation Registration Theory. We developed a research with qualitative approach of the case study type. As possible results, we observed that the students used mereological, positional and reconfiguration modifications in their resolution procedures. We also observe that in problem situations that contain pictures as part of the utterance, attention must be paid to the purpose of the situation.

Keywords: Problem situation. Flat Geometry. Record of Semiotic Representation. Congruence.

\section{Introdução'}

Em andamento na Universidade Estadual do Sudoeste da Bahia (UESB), campus Jequié, o projeto de pesquisa baseado numa proposta de intervenção no ensino da Geometria nos anos

\footnotetext{
1 Uma primeira versão deste artigo foi publicada nos anais do XVIII Encontro Baiano de Educação Matemática, realizado em llhéus (BA), em julho de 2019.
} 
iniciais da formação de professores, tem como intuito abordar temáticas relacionadas à problematização de conceitos de representações e conversões vinculadas ao ensino e a aprendizagem da Geometria. Em função desse aspecto, foi proposta uma situação-problema aos alunos ingressantes no primeiro semestre letivo de 2017 do curso Licenciatura em Matemática da UESB. Essa proposta tinha por base a teoria de Registro de Representação Semiótica de Raymond Duval. Sobre a teoria, mais específico relacionado à semiótica, este teórico, salienta que:

\begin{abstract}
[..] são produções constituídas pelo emprego de signos pertencentes a um sistema de representações que tem inconvenientes próprios de significação e de funcionamento. Uma figura geométrica, um enunciado em língua natural, uma fórmula algébrica, um gráfico são representações semióticas que exibem sistemas semióticos diferentes. Consideram-se, geralmente, as representações semióticas como um simples meio de exteriorização de representações mentais para fins de comunicação, quer dizer para torná-las visíveis ou acessíveis a outrem. Ora, este ponto de vista é enganoso. As representações não são somente necessárias para fins de comunicação, elas são igualmente essenciais à atividade cognitiva do pensamento. (DUVAL, 2012, p. 269)
\end{abstract}

Segundo Duval (2012), para que um sistema semiótico possa ser um registro de representação, devem permitir as três atividades cognitivas fundamentais ligadas à semiose:

- A formação de uma representação identificável como uma representação de um registro dado: enunciação de uma frase - compreensível numa língua natural dada -, composição de um texto, desenho de uma figura geométrica ou não, elaboração de um esquema, expressão de uma fórmula etc.

- O tratamento de uma representação é a transformação desta representação no mesmo registro onde ela foi formada. Portanto, tratamento é uma transformação estritamente interna a um registro.

- A conversão de uma representação é a transformação desta função em uma interpretação em outro registro, conservando a totalidade ou uma parte somente do conteúdo da representação inicial.

Duval identificou quatro tipos de apreensões na resolução de problemas em Geometria, sendo estas descritas a seguir:

Apreensão perceptiva: é a interpretação das formas da figura em uma situação geométrica; 


\begin{abstract}
Apreensão discursiva: é a interpretação dos elementos da figura geométrica, privilegiando a articulação dos enunciados, levando em consideração a rede semântica de propriedades do objeto;

Apreensão sequencial: é solicitada nas tarefas de construção ou nas tarefas de descrição com objetivo de reproduzir uma figura;

Apreensão operatória: está centrada nas modificações possíveis de uma figura de partida e na reorganização perceptiva que essas modificações sugerem. (DUVAL, 1995 apud ALMOULOUD, 2003, p. 127)
\end{abstract}

No entender de Duval (2011), ver uma figura é reconhecer imediatamente as formas em que são observados os contornos justapostos, superpostos e separados. Dessa forma, é possível manipular a figura física ou mentalmente sobre o todo ou apenas em parte da figura. Sobre a apreensão operatória, a classificação das modificações pode ser da seguinte forma:

Modificação mereológica: a figura pode separar-se em partes que são subfiguras da figura dada, fracionando-se e reagrupando-se, isto é uma relação da parte e do todo;

Modificação ótica: e a transformação de uma figura em outra considerada sua imagem;

Modificação posicional: e o deslocamento em a um referencial. (DUVAL, 1995 apud ALMOULOUD, 2003, p. 127)

Para este trabalho, nosso principal questionamento foi: Quais são as influências da figura nos procedimentos de resolução de uma situação-problema de Geometria plana? Que cuidados devem ser tomados ao se propor uma situação problema que parte de sua interpretação depende de figuras?

A seguir, apresentaremos a situação-problema proposta aos estudantes e sua análise à priori.

\title{
2 Análise à priori
}

Em se tratando de problemas geométricos, Duval (1995), citado por Almouloud (2003), percebe três níveis de problemas:

- Nível 1: aqueles em que há congruência operatória da figura e um tratamento matemático, neste caso uma apreensão discursiva explicita não é necessária.

- Nível 2: aqueles em que a apreensão discursiva é necessária, porque não há mais congruência da figura ou porque é explicitamente pedido como justificativa. 
- Nível 3: aqueles que exigem mais que uma apreensão discursiva, o recurso aos esquemas formais lógicos específicos tais como o raciocínio disjuntivo, o raciocínio por contraposição.

A situação-problema proposta aos estudantes do primeiro semestre da Licenciatura em Matemática é apresentada abaixo

\begin{abstract}
0 quadrado representado abaixo está subdividido em sete peças geométricas, constituindo um quebra-cabeça denominado Tangram. Assinale a alternativa correspondente à fração que representa a região sombreada da figura
\end{abstract}
a) $3 / 7$.
b) $1 / 7$.
c) $3 / 4$.
d) $4 / 7$.
e) $1 / 4$.

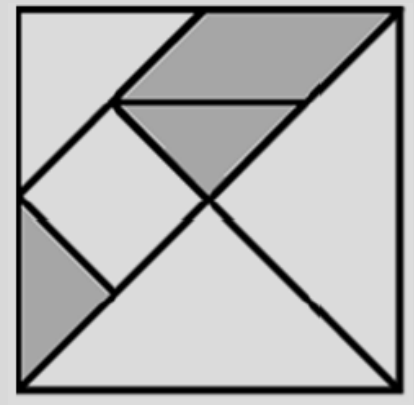

O objetivo da situação-problema é avaliar se o sujeito resolvedor identifica a relação das partes do quebra-cabeça com a totalidade de peças do jogo por meio de número racionais na forma de frações.

Nesse caso, os estudantes, para resolver a questão, necessitavam fazer conversões, uma vez que, o registro solicitado como resposta para a questão geométrica está na forma de fração. Um procedimento para solucionar o problema seria, primeiramente, os estudantes fazer 0 tratamento da informação, no âmbito geométrico, percebendo que o triângulo pequeno do Tangram recobre todas as figuras do quebra-cabeça e observando quantas vezes se dá cada recobrimento. Daí se percebe a relação entre a área da peça menor do jogo com a totalidade da área das peças. Finalizando o tratamento, basta observar quantas peças estavam sombreadas na questão, para só no fim fazer a conversão de registro e obter a resposta correta. Outro procedimento de resolução seria primeiro fazer a conversão, isto é, perceber que a peça triângulo pequeno equivale a $\frac{1}{16}$ da totalidade da área das peças do jogo e, a partir daí, obter $\frac{4}{16}$, para fazer o tratamento no outro registro (simplificação) e assinalar a resposta correta $\frac{1}{4}$.

Almouloud (2003), citando Duval (1995), delineia três critérios para determinação do grau de congruência entre os registros, a saber: 
1. Possibilidade de uma correspondência lexical (semântica) ou correspondência uma a uma entre os elementos significantes: para cada elemento simples no registro de saída tem um elemento simples correspondente no registro de chegada.

2. A unicidade semântica terminal: cada unidade significante no registro de saída tem uma única unidade significante no registro de chegada.

3. A ordem que compõe cada uma das representações: diz respeito à forma de apresentação de cada uma das representações.

Quando uma destas três condições descritas acima não está satisfeita, a conversão é não congruente.

Observamos que todos os critérios acima estão satisfeitos, isto é, em qualquer um dos sentidos no processo de resolução admite a congruência, uma vez que a atividade estava muito próxima de uma decodificação. Sendo assim, a atividade é classificada no nível 1.

Para além da situação-problema, foi proposto um questionário inerente ao ensino da Geometria durante a Educação Básica para os estudantes que participaram da atividade. As perguntas apresentadas foram:

1. O Que você entende por Geometria?

2. Dos conteúdos relacionados à Geometria estudados na Educação Básica, quais foram apropriados por você?

3. Com relação a esses conteúdos, quais as principais dificuldades encontradas? Essas dificuldades foram vencidas posteriormente? Se sim, como?

4. Você já frequentou outro curso de graduação? Em caso afirmativo, como acredita que este curso contribui para a sua formação em termos de conhecimentos geométricos?

O objetivo de questionarmos aos estudantes sobre sua experiência com conteúdos de Geometria era o de obter informações acerca de que conhecimentos poderiam lançar mão no momento da resolução da situação-problema.

Finalizando a atividade foi entregue a cada estudante um Tangram de madeira. A ideia era que, aqueles que porventura estivessem em dúvida com relação ao procedimento de resolução realizado, pudessem refletir sobre tal ação. Por isso, anexamos as seguintes perguntas ao final da atividade: 
Quais relações foram percebidas por meio da manipulação das peças do Tangram?

Relatar se essa manipulação auxiliou ou não na resolução da situação problema.

\section{Análise dos dados}

Caracterizamos esta pesquisa como qualitativa, do tipo estudo de caso (LÜDKE e ANDRÉ, 1986), por ser algo singular, específico deste grupo de alunos investigados. Foram alvo dessa pesquisa 17 estudantes do $1^{\circ}$ semestre, ingressantes de 2017, da Licenciatura em Matemática da UESB, campus Jequié. Foi utilizado o Termo de Consentimento Livre e Esclarecido para garantir o direito de escolha em participar ou não da pesquisa. 0 referido Termo foi lido e explicado aos participantes, em seguida assinado pelos mesmos.

0 instrumento utilizado foi uma situação-problema, escolhida pelo grupo de pesquisadores. Ao responder a situação, os estudantes foram orientados para que registrassem os procedimentos ou o raciocínio que tiveram ao resolver. 0 critério para a escolha dos participantes da pesquisa foi que estes ainda estivessem na primeira semana de aula, portanto, sem contato com o conteúdo de Geometria plana, disciplina ofertada no primeiro semestre do curso. $O$ instrumento de coleta de dados foi aplicado pela professora de Geometria plana da turma. Para a análise que apresentaremos, escolhemos os registros de quatro participantes. Com 0 propósito de manter o sigilo sobre a identidade destes participantes, eles puderam escolher um codinome. Assim apresentaremos a análise dos registros de Oliver, SKFF, Florzinha e Branco.

\section{Análise do questionário proposto aos participantes}

Com o objetivo de conhecer a concepção dos alunos em relação à Geometria, questionamos o que entendiam por essa área da Matemática, cujas respostas foram:

Oliver: É o estudo de figuras ou sólidos através de medidas e fórmulas para identificar áreas, volumes, etc.

SKFF: $O$ estudo das medidas das formas geométricas.

Branco: É o estudo das figuras geométricas, cálculos dos seus lados para definir sua área. 
Florzinha: São estudos de formas geométricas que dão noção de espaço e volume. Além de apresentar formas que ajudam a identificar espaços em tamanhos maiores ou até mesmo menores.

Para todos os participantes, o conceito de Geometria está relacionado à figura e à medida. Fazendo uma comparação com o dicionário, Geometria é definida como "parte da Matemática cujo objeto é o estudo do espaço e das figuras que podem ocupá-lo" (BUENO, 2007). Por outro lado, há o significado relacionado aos termos gregos "geo" (terra) e "métron" (medir). Assim, notamos que a percepção dos alunos com relação à Geometria está correta. Observamos, porém, que nenhum dos participantes classificou a Geometria como parte da Matemática, talvez por que em muitas escolas ela é ofertada como uma disciplina separada.

Posteriormente, perguntamos se dos conteúdos relacionados à Geometria, estudados na Educação Básica, quais foram apropriados por eles. E as respostas dos estudantes foram as seguintes:

Oliver: Relações métricas no triângulo retângulo, cones e cilindro, volume.

SKFF: Não recordo.

Branco: Cálculo da área de triângulos.

Florzinha: Geometria plana.

Sobre as respostas dos estudantes, percebemos que se resume basicamente à Geometria plana; apenas um cita conteúdos de Geometria espacial. No geral, as respostas são superficiais e vagas.

A terceira questão fazia menção às respostas dadas na segunda, isto é, com relação a esses conteúdos, quais as principais dificuldades encontradas e se essas dificuldades foram vencidas posteriormente. Em caso afirmativo, como? As respostas obtidas foram:

Oliver: Os conteúdos estudados muitas vezes não eram completos, ficando para trás as partes mais complexas dos conteúdos.

SKFF: Tive muita dificuldade na parte de geometria.

Branco: Conseguir decorar alguns valores de ângulos e tabelas de seno, cosseno e tangente.

Florzinha: Identificação de figura dentro da outra e os ângulos.

É interessante observar que apesar de dizer não se recordar dos conteúdos de Geometria estudados, SKFF afirmou ter tido muita dificuldade nos conteúdos de Geometria dados na 
Educação Básica. Dos quatro participantes, apenas os dois últimos responderam o restante da questão. Segundo Florzinha, "as dificuldades não foram vencidas até a atualidade", já para Branco elas "foram vencidas com bastante prática".

A última questão fazia relação com alguma formação anterior que os discentes pudessem ter tido, perguntamos: Você já frequentou outro curso de graduação? Em caso afirmativo, como acredita que este curso contribui para a sua formação em termos de conhecimentos geométricos?

Oliver respondeu que sim, curso de Administração de Empresas, porém foram apenas 15 dias de aulas. Já SKFF parece não ter entendido o teor da pergunta e respondeu: Gosto de Matemática, identifico bem com a parte financeira, porém pretendo aprender as demais áreas. Florzinha afirmou que já frequentou outro curso de graduação, porém, não contribuiu para a formação em termos de conhecimentos matemáticos. Já Branco, não frequentou outro curso de graduação.

Por meio das respostas dos alunos às questões propostas, observamos que com relação aos conteúdos de Geometria ensinados, basicamente ficam restritos as relações métricas do triângulo retângulo e o cálculo de área. Os estudantes também citam que as dificuldades encontradas na aprendizagem desses conteúdos em sua maioria não foram vencidas. Segundo Almouloud et al. (2004), "muitos tópicos de Matemática, pelo fato de não serem planejados ou ensinados pelos professores, não são aprendidos por seus alunos". Os autores ainda exemplificam, citando que, embora os professores indiquem a Geometria como item importante, que merece lugar em todos os níveis de ensino, não há concordância quanto à seleção e à organização dos conteúdos a serem ensinados tanto no Ensino Fundamental como no Ensino Médio.

A fala de Oliver explicita essa questão quanto diz que "Os conteúdos estudados muitas vezes não eram completos, ficando para trás as partes mais complexas dos conteúdos." A seguir faremos a análise a posteriori dos registros dos alunos frente à situação-problema a eles proposta.

\section{Análise dos procedimentos de Oliver}

Posteriormente a leitura do enunciado, Oliver se direciona para a realização dos cálculos, sem fazer nenhum registro descritivo do que foi pensado para a resolução do problema. Com isso, a partir das divisões feitas pelo aluno na figura, conjecturamos, em primeira análise, que: 
i) Primeiramente Oliver divide o quadrado em dois triângulos isósceles.

ii) Em seguida, ele subdivide um dos triângulos isósceles em triângulos menores - são as linhas em vermelho.

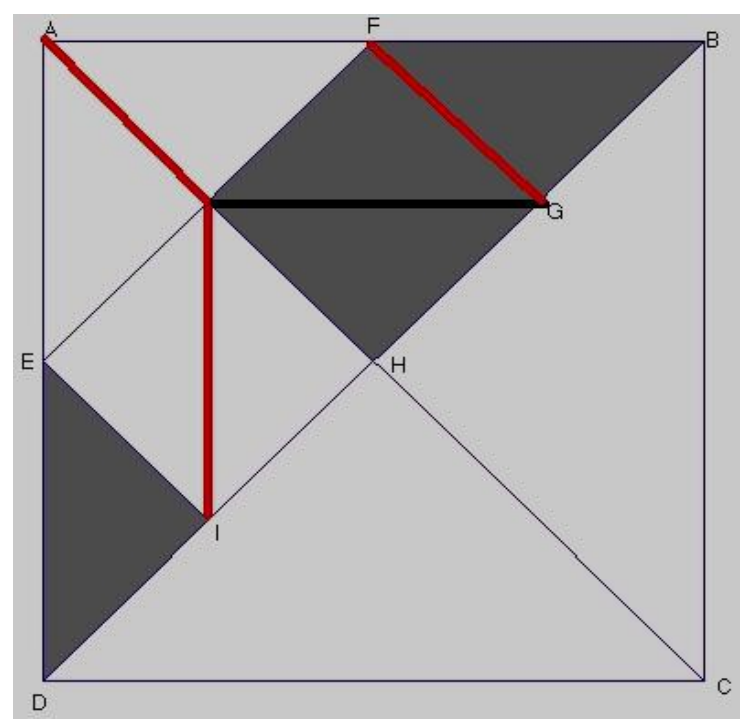

Figura 1: Figura modificada por Oliver (Dados da Pesquisa)

iii) Após isso, ele efetua o seguinte cálculo:

$$
\frac{1}{2} \times \frac{4}{8}=\frac{4}{16}=\frac{1}{4}
$$

Em segunda análise, percebemos que houve uma modificação mereológica (DUVAL, 1995 apud ALMOULOUD, 2003), visto que houve o fracionamento e o reagrupamento da figura dada. Além disso, nota-se que houve uma reconfiguração "operação que consiste em organizar uma ou várias subfiguras diferentes de uma figura dada em outra" (ALMOULOUD, 2003, p. 127).

Seguidamente, sobre a manipulação do Tangram, Oliver destaca que "as peças foram feitas na proporção onde a menor delas se juntava formando as maiores" (modificação posicional e reconfiguração). Ainda, relata que a manipulação auxiliou para "verificar a veracidade da resposta encontrada".

\section{Análise dos procedimentos de SKFF}

Subsequente à leitura do enunciado, SKFF aponta que "a figura representa, ao todo, sete partes e as partes sombreadas contém três partes do todo. Representando, portanto, $\frac{3}{7}$. Depois 
da manipulação, constatei que a alternativa correta seria $\frac{4}{7} \cdot$." Em oposição a Oliver, SKFF não faz divisões na figura.

Sobre a manipulação do Tangram, SKFF relata que "o quadrado pode ser dividido em várias peças, como: triângulo, quadrado, losango..." reafirmando assim a modificação mereológica e a reconfiguração da figura dada. Ainda, afirma que a manipulação auxiliou para a verificação do resultado e ressalta que "as partes sombreadas foram fundamentais para a resolução do problema”.

No entanto, percebe-se que SKFF utiliza da apreensão perceptiva quando fez a relação entre a quantidade de peças do jogo e a quantidade de peças sombreadas. Observamos que, mesmo quando o estudante manipulou as peças do Tangram concretamente, continuou levando em consideração a relação entre o número de peças sombreadas e o número de peças do jogo. A única modificação foi que ele visualizou os quatro triângulos pequenos nas peças sombreadas.

\section{Análise dos procedimentos de Branco}

Com relação à resolução da situação-problema, Branco realizou interferências na figura dividindo o triângulo médio ao meio, de modo a perceber a relação entre as quatro peças sombreadas e a figura total. Presumimos que mentalmente Branco reposiciona o triângulo pequeno do Tangram sobre parte dividida do triângulo médio, como ilustramos na Figura 2.

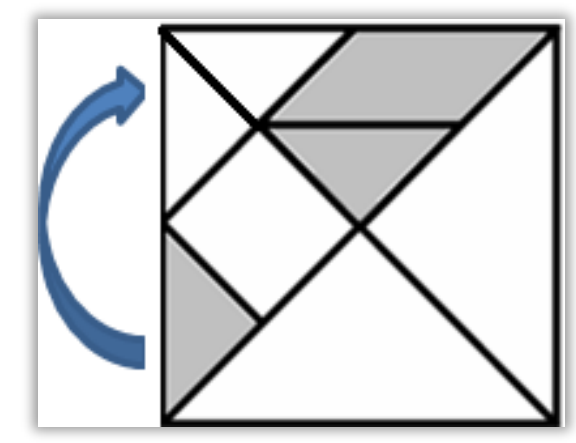

Figura 2: Interferência feita por Branco (Dados de Pesquisa)

Nessa resolução percebemos que o estudante realiza inicialmente tratamentos dentro do registro geométrico, em seguida faz a conversão e assinala a resposta correta. Essa percepção se dá por meio de uma modificação posicional na figura. 
Como pode ser observado pelas falas de Branco — "em relação à área do quadrado a área sombreada equivale a $\frac{1}{4}$ " e "Em relação à quantidade de pecas sombreadas é $\frac{3}{7}$ " - 0 estudante apresenta dúvidas com relação ao objetivo da situação, o que o levou a oferecer duas respostas distintas.

Em relação à questão sobre quais relações foram percebidas por meio da manipulação do Tangram, o estudante respondeu "perceber que a área pintada corresponde a 25\% da área do quadrado (figura total)"

Questionado se essa manipulação auxiliou ou não na resolução da situação-problema, a resposta foi "sim, pois confirmou minha tese da resposta 1".

\section{Análise dos procedimentos de Florzinha}

Florzinha não realizou nenhum tipo de cálculo, faz intervenções na figura, da mesma forma que Oliver na Figura 1 e, assinalou de forma errônea a alternativa $\frac{3}{4}$. Dessa forma, concluímos que a aluna fez modificações - tratamento geométrico - na figura, mentalmente fez conversão do registro figural para o algébrico, mas não conseguiu chegar à resposta correta, por não visualizar as proporções das áreas entre as figuras.

Sobre a manipulação do Tangram, Florzinha afirmou: "Não ajudou na resolução, pois independente da sua posição sempre terei a mesma região sombreada independente de onde for localizada".

\section{Considerações e perspectivas}

Entendemos que o problema posto aos estudantes Oliver, Skff, Florzinha e Branco constitui-se com características do nível 1 , segundo a classificação de problemas geométricos proposta por Duval $(2011,2012)$. Quanto à resolução dos estudantes eles utilizaram de modificações mereológicas, posicionais e reconfigurações na figura para responder a situaçãoproblema, contudo, o fato de ser mais visível na figura a relação entre peças sombreadas e 0 número total de peças, levou os estudantes a se confundirem sobre a solicitação feita.

Voltando às questões iniciais - Quais são as influências da figura nos procedimentos de resolução de uma situação problema de Geometria plana? Que cuidados devem ser tomados ao 
se propor uma situação-problema que parte de sua interpretação depende de figuras? -, avaliamos que a figura tem um papel crucial na interpretação da atividade, porém, essa interpretação depende de como é feita a solicitação, possivelmente pode não ter ficado claro que a relação pedida era entre área sombreada e a área total da figura, muitos participantes marcaram equivocadamente a opção (a) ou ficaram na dúvida entre a opção (a) e a opção (e) na hora de oferecer uma resposta final.

Outro ponto, considerávamos que a manipulação concreta do Tangram pudesse levar os estudantes a refletirem sobre os próprios procedimentos de modo que respondessem de forma correta a situação. 0 que ocorreu, segundo relato dos próprios estudantes, foi que eles apenas confirmaram suas respostas, fossem erradas ou certas.

A situação-problema proposta enfatizou as apreensões perceptiva e operatória. Para além desse estudo, continuamos investigando se situações-problema que abarcam os quatro tipos de apreensões - perceptiva, discursiva, sequencial e operatória - poderiam minimizar os problemas de interpretação que foram percebidos com relação à situação-problema proposta.

\section{Referências}

ALMOULOUD, Saddo Ag. Registros de representação semiótica e compreensão de conceitos geométricos. In: MACHADO, Sílvia Dias Alcântara. (Org.). Aprendizagem em Matemática: registros de representação semiótica. Campinas: Papirus, 2003. p. 125-147.

ALMOULOUD, Saddo Ag; MANRIQUE, Ana Lúcia; SILVA, Maria José Ferreira da; CAMPOS, Tânia Maria Mendonça. A Geometria no Ensino Fundamental: reflexões sobre uma experiência de formação envolvendo professores e alunos. Revista Brasileira de Educação, Rio de Janeiro, n. 27, p. 94-108, set./dez. 2004.

BUENO, Silveira. Minidicionário da Língua Portuguesa. 2. ed. São Paulo: FTD, 2007.

DUVAL, Raymond. Registros de representação semiótica e funcionamento cognitivo do pensamento. Tradução de Méricles Thadeu Moretti. Revemat, Florianópolis, v. 7, n. 2, p. 266-297, jul./dez. 2012.

DUVAL, Raymond. Ver e ensinar a Matemática de outra forma. Entrar no modo matemático de pensar. os registros de representações semióticas. Tradução de Marlene Alves Dias. São Paulo: Proem. 2011.

LÜDKE, Menga; ANDRÉ, Marli. Pesquisa em Educação: abordagens qualitativas. São Paulo: EPU, 1986. 